\title{
Lipid profiles of patients presenting with acute myocardial infarction in a South African regional hospital
}

\section{A. Sirkar, D. Sadhabiriss and S.L. Brown}

Division of Internal Medicine, School of Clinical Medicine, College of Health Sciences, University of KwaZulu-Natal, Durban, South Africa

Address for correspondence:

\section{A. Sirkar}

Division of Internal Medicine

School of Clinical Medicine

College of Health Sciences

University of KwaZulu-Natal

719 Umbilo Road

Durban

4001

South Africa

Email:

atishsirkar@live.com

\section{INTRODUCTION}

Cardiovascular disease (CVD) is I of the most frequent causes of death in developing and developed nations. In 2011, the World Health Organisation (WHO) estimated annual deaths from CVD at more than 17 million, of which 7.6 million were due to ischaemic heart disease resulting in an acute myocardial infarction (AMI).(I) In South Africa, CVD is the second most prevalent cause of death after HIV-associated disease, and accounts for up to $40 \%$ of deaths among adults.(2)

AMI typically follows the rupture of an atherosclerotic plaque, with resultant platelet aggregation and thrombotic occlusion. Modifiable risk factors for atherosclerosis include hyperlipidaemia, smoking, hypertension, diabetes mellitus (DM), abdominal obesity and physical inactivity. ${ }^{(3,4)}$ These risk factors synergistically increase the overall risk of development of an AMI, regardless of gender or age.(5) Increased levels of lowdensity lipoprotein cholesterol (LDL-C) and decreased levels of high-density lipoprotein cholesterol (HDL-C) play a pivotal role in atherogenesis and are associated with a higher risk of development of coronary artery disease (CAD). ${ }^{(6-8)}$

Statin therapy has been implemented in both primary and secondary prevention of CAD.(9) Statin therapy following an $\mathrm{AMI}$ has been shown to be effective in reducing mortality by at

\section{ABSTRACT}

Background: Cardiovascular disease is an important cause of morbidity and mortality in South Africa and hyperlipidaemia is a major contributing modifiable risk factor.

Objectives: To describe the lipid profiles of patients with acute myocardial infarction and to compare values with recommended target levels outlined in the South African Dyslipidaemia Guideline Consensus Statement. Methods: We performed a retrospective chart review of patients admitted with a diagnosis of acute myocardial infarction to a regional hospital in Durban, South Africa, between I January and 3 I December 2016. Patients had a non-fasting lipogram taken within the first $\mathbf{2 4}$ hours of admission.

Results: We enrolled 126 subjects. The mean age was 57.6 (SD \pm 9.4 ) years. One hundred and ten subjects (87.3\%) met criteria for hyperlipidaemia. Previous statin therapy was associated with lower LDL-cholesterol values $(3.43 \mathrm{mmol} / \mathrm{L}$ vs. $4.03 \mathrm{mmol} / \mathrm{L}, \mathrm{p}=0.02)$, but only 9 (II.2\%) of the 80 subjects on therapy (88.8\%) fell below the levels recommended for their risk category by the South African Dyslipidaemia Guideline Consensus Statement. Overall, 23 subjects ( $18.3 \%$ of the entire study group) demonstrated LDL-C values at presentation that were below the recommended values.

Conclusions: A high proportion of subjects presenting with acute myocardial infarction show evidence of suboptimal control of pre-existing hyperlipidaemia. SAHeart 2018;15:202-209

least 10\%, as well as reducing major cardiac events by $23 \%$ for every $1.0 \mathrm{mmol} / \mathrm{L}$ reduction in LDL-C. ${ }^{(5)} \mathrm{A}$ lipid profile should be performed at the time of admission, together with the initiation of statin therapy. Lipid profiles should be repeated 4 - 6 weeks after discharge. The South African Dyslipidaemia Guideline Consensus Statement (SADGCS) recommends a target LDL-C value less than $1.8 \mathrm{mmol} / \mathrm{L}$ for subjects considered to be at very high risk of cardiovascular events..$^{(5)}$

In this study we set out to determine the prevalence of hyperlipidaemia in subjects admitted with AMI to an urban regional hospital in KwaZulu-Natal, and to determine the association of lipid levels with previous statin therapy - thus estimating the extent to which hyperlipidaemia contributes to the incidence of $\mathrm{AMI}$ in our population. 


\section{SUBJECTS AND METHODS}

The study site is a 350-bed regional hospital in Durban, KwaZulu-Natal, which services the communities of Phoenix, Inanda, Amaoti and Mount Edgecombe, with most of this population being represented by people of Indian and African descent. Patients with AMI are managed in the general medical ward as the hospital does not have critical care facilities.

We performed a retrospective chart review of all patients aged 18 years or older, admitted with an AMI from I January 3I December 2016. The diagnosis of AMI was based on a history of typical ischaemic chest pain, and elevated Troponin T levels, with or without typical electrocardiographic (ECG) changes. ST-elevation myocardial infarction (STEMI), was defined as the presence of significant ST elevations or new LBBB on ECG and non-ST-elevation myocardial infarction (NSTEMI) was defined as absence of ST elevation with or without ST depression or T wave inversions.

All patients had a non-fasting lipogram taken within the first 24 hours of admission, which included total cholesterol (TC), HDL-C, triglycerides (TG) and calculated LDL-C. Patients were diagnosed with hyperlipidaemia if their TC exceeded $5.0 \mathrm{mmol} / \mathrm{L}$, LDL-C values were more than $3.0 \mathrm{mmol} / \mathrm{L}$, and $\mathrm{HDL}-\mathrm{C}$ less than $1.0 \mathrm{mmol} / \mathrm{L}$ or $1.2 \mathrm{mmol} / \mathrm{L}$ for males and females respectively. A target $L D L-C$ value less than $1.8 \mathrm{mmol} / \mathrm{L}$ was used for subjects considered to be at very high risk of cardiovascular events. For the purpose of this study, those subjects with abnormal lipid parameters (raised LDL-C, raised TC or low HDL-C) were further subclassified into mixed hyperlipidaemia (3 abnormal parameters), combined hyperlipidaemia (2 abnormal lipid parameters) and isolated (single parameter) hyperlipidaemia.

Data on prevalence of risk factors were also documented. Premature CAD was defined as CAD diagnosed in males before 55 years of age and in females before 60 years, as per the SADGCS. ${ }^{(5)}$ The target value for glycated haemoglobin $\left(\mathrm{HbA}_{\mid c}\right)$ was less than $7 \%$, as recommended by 2012 SEMDSA guidelines.

Data was captured on a data collection sheet and collated using a Microsoft Excel ${ }^{\circledR}$ spreadsheet (Microsoft Office 2016 , Microsoft Corporation, Redmond WA, USA). Statistical analysis was performed using Statistical Package for the Social Sciences (SPSS) version 24.0 (SPSS Statistics for Windows, IBM Corp., Armonk, NY) and MedCalc Statistical Software version 18.6 (MedCalc Software bvba, Ostend, Belgium). Ethical clearance was obtained from the Biomedical Research Ethics Committee of the University of KwaZulu-Natal (authorisation BE:394/I7). The hospital management of Mahatma Gandhi Memorial Hospital and the KwaZulu-Natal Department of Health provided the relevant permissions.

Continuous variables with a normal distribution are expressed as mean and standard deviation ( \pm SD), and means are compared using Student's t test or ANOVA. Categorical variables were evaluated by chi-square or Fisher's exact test. A twotailed $p$ value $<0.05$ was considered statistically significant.

\section{RESULTS}

During the study period, 154 subjects presented to the emergency department with a suspected diagnosis of AMI. Twenty eight were excluded, leaving a final sample of 126 subjects (Figure 1). The demographic profile, clinical presentation and risk profile of the subjects is shown in Table I. One hundred and nineteen subjects were of Indian descent and 7 of African descent. Females had a significantly higher incidence of premature CAD (81.3\%) than males (38.5\%, $p<0.000$ I). Seventy seven $(61.1 \%)$ subjects showed evidence of NSTEMI and 49 (38.9\%) showed evidence of STEMI.

The mean number of risk factors per subject was 3.45. Hypertension and DM were significantly more prevalent in female subjects. The mean glycated haemoglobin $\left(\mathrm{HbA}_{l c}\right)$ values of all tested subjects were significantly higher in females than in males. Females demonstrated significantly less association with smoking and family history of CAD than males. We did not demonstrate a significant difference between men and women for age, mean number of risk factors, prevalence of pre-

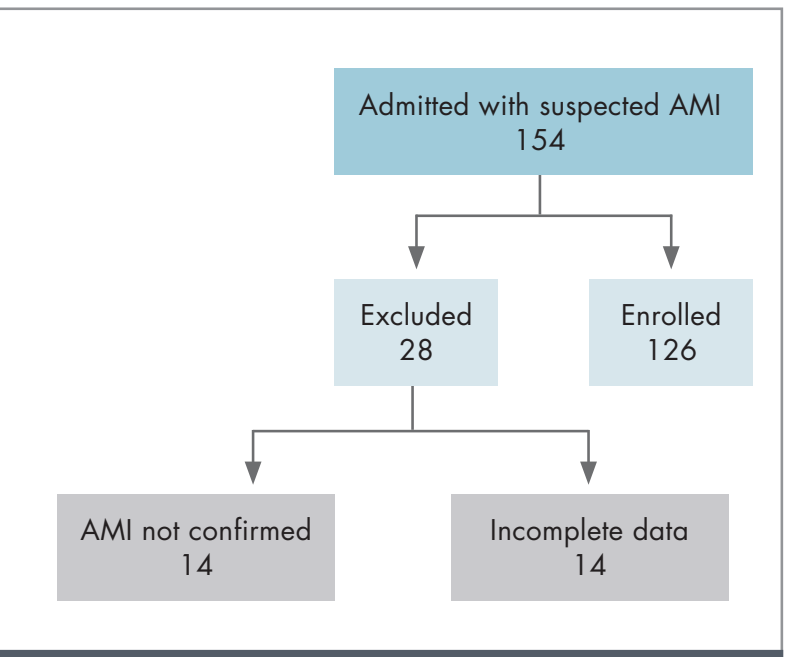

FIGURE I: Constitution of the final study group (AMI: acute myocardial infarction). 
TABLE I: Demographics of the study population.

\begin{tabular}{|c|c|c|c|c|}
\hline Parameter & Males & Females & Total & $\mathrm{P}$ value* \\
\hline No. of subjects & $78(61.9 \%)$ & $48(38.1 \%)$ & 126 & 0.008 \\
\hline Mean age (years) & $57.5(\mathrm{SD} \pm 8.99)$ & $57.7(S D \pm 10.4)$ & $57.6(\mathrm{SD} \pm 9.4)$ & 0.873 \\
\hline Premature CAD (presentation <60 years) & $30(38.5 \%)$ & $39(81.3 \%)$ & $69(54.8 \%)$ & $<0.000$ । \\
\hline Ethnicity & & & & 0.593 \\
\hline Indian descent & 73 (93.6\%) & $46(95.8 \%)$ & $119(94.4 \%)$ & \\
\hline African descent & $5(6.4 \%)$ & $2(4.2 \%)$ & $7(5.6 \%)$ & \\
\hline Type of AMI & & & & 0.079 \\
\hline STEMI subtype & 35 (44.9\%) & $14(29.2 \%)$ & 49 (38.9\%) & 0.074 \\
\hline NSTEMI subtype & $43(55.1 \%)$ & $34(70.8 \%)$ & 77 (61.1\%) & \\
\hline \multicolumn{5}{|l|}{ Risk Factors } \\
\hline Hyperlipidaemia & $66(60 \%)$ & 44 (40\%) & $110(87.3 \%)$ & 0.248 \\
\hline Previously diagnosed & $47(58.8 \%)$ & $33(41.2 \%)$ & $80(63.5 \%)$ & \\
\hline New diagnosis & $19(63.3 \%)$ & II (36.7\%) & $30(23.8 \%)$ & \\
\hline Diabetes mellitus & $42(53.8 \%)$ & $35(72.9 \%)$ & $77(61.1 \%)$ & 0.03 \\
\hline Mean $\mathrm{HbA}_{\mathrm{Ic}}(\%)$ & $7.8(S D \pm 2.2)$ & $8.9(S D \pm 2.6)$ & $8.23(\mathrm{SD} \pm 2.5)$ & 0.023 \\
\hline Hypertension & $47(60.3 \%)$ & $40(83.3 \%)$ & $87(69 \%)$ & 0.007 \\
\hline Smoker & $56(71.8 \%)$ & $7(14.6 \%)$ & $63(50 \%)$ & $<0.000$ । \\
\hline Family history of CAD & $54(69.2 \%)$ & $21(43.8 \%)$ & 75 (59.5\%) & 0.005 \\
\hline Previous ACS & $21(26.9 \%)$ & 10 (20.8\%) & 31 (24.6\%) & 0.041 \\
\hline Alcohol use & $13(16.7 \%)$ & I (2.1\%) & $14(11.1 \%)$ & 0.011 \\
\hline Mean risk factors per patient & $3.62(1.36)$ & $3.19(1.36)$ & $3.45(1.37)$ & 0.89 \\
\hline Mean LOS (days) & $6.38(\mathrm{SD} \pm 1.54)$ & $6.39(S D \pm 1.60)$ & $6.39(S D \pm 1.55)$ & 0.995 \\
\hline
\end{tabular}

ACS = Acute coronary syndrome, AMI = Acute myocardial infarction, CAD = Coronary artery disease, LOS = Length of stay, NSTEMI = Non-ST elevation myocardial infarction, STEMI = ST elevation myocardial infarction, SD = Standard deviation. "Denotes $p$ value when comparing males with females.

vious acute coronary syndrome (ACS), or mean length of stay (Table I). Thirty one (24.6\%) subjects had a previous AMI. In comparison with the subjects experiencing a first AMI, this group did not differ significantly in terms of gender, age, smoking history, hypertension or alcohol use (data not shown). They were, however, more likely to have a family history of CAD: 24 of $31(77.4 \%)$ vs. 51 of $95(53.7 \%, p=0.02)$ and to have DM: $25(80.6 \%)$ vs. $52(54.7 \%, p=0.01)$.

We noted a high prevalence of combined and mixed hyperlipidaemia (Figure 2). The distribution of values for each lipoprotein is shown in Table II. There were no statistically significant differences in lipid profile between males and females. Eighty subjects had received prior therapy with either simvastatin or atorvastatin (Table III). No subject was reported as having used fibrates or other lipid-lowering agents. We noted a

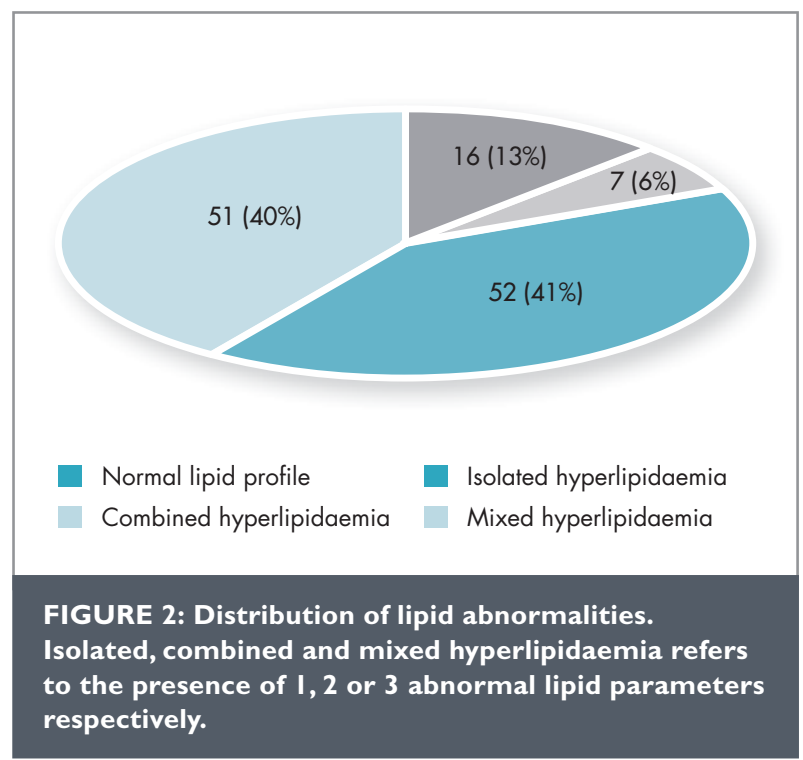


significantly lower LDL-C and lower incidence of STEMI in those who had received statin therapy. There were no significant differences in other lipid parameters between these 2 groups. There was no significant difference in lipid levels between diabetic and non-diabetic subjects, and no significant correlation between lipid levels and the extent of diabetic control (Table IV). Poor lipid control was seen in subjects with both controlled and poorly controlled DM, as assessed by $\mathrm{HbA}_{\mathrm{lc}}$ levels. Diabetic patients were significantly more likely to demonstrate an NSTEMI.

The distribution of LDL-C values is shown in Figure 3, categorised by risk and by statin therapy. Few subjects, irrespective of risk category or of statin therapy, had LDL-C values below the SADGCS-recommended levels (Table V). No lipid parameter differed significantly between those subjects with a previous $A M I$ and those with a first AMI (data not shown). There was no significant difference in the number of subjects with and without a previous AMI whose LDL-C value was below the target level recommended for their risk category, as defined above: 4 of 31 ( $12.9 \%)$ vs. 19 of 95 (20.0\%, $p=0.44)$. There was also no significant difference in the number of diabetic subjects with and without previous AMI with an optimal glycated haemoglobin value: 9 of 24 (37.5\%) vs. 22 of 7 I $(31.0 \%, p=0.62)$.

\section{TABLE II: Lipid profiles.}

\begin{tabular}{|l|l|l|l|}
\hline \hline Lipid component & Male $(\mathrm{n}=78)$ & Female $(\mathrm{n}=48)$ & Total $(\mathrm{n}=126)$ \\
\hline Total cholesterol $(\mathrm{mmol} / \mathrm{L})$ & $5.19(\mathrm{SD} \pm 1.33)$ & $5.50(\mathrm{SD} \pm 1.69)$ & $5.31(\mathrm{SD} \pm 1.48)$ \\
\hline LDL-C $(\mathrm{mmol} / \mathrm{L})$ & $3.27(\mathrm{SD} \pm 1.19)$ & $3.55(\mathrm{SD} \pm 1.50)$ & $3.39(\mathrm{SD} \pm 1.32)$ \\
\hline HDL-C $(\mathrm{mmol} / \mathrm{L})$ & $0.99(\mathrm{SD} \pm 0.28)$ & $1.10(\mathrm{SD} \pm 0.36)$ & $1.03(\mathrm{SD} \pm 0.32)$ \\
\hline Triglycerides $(\mathrm{mmol} / \mathrm{L})$ & $2.08(\mathrm{SD} \pm 1.22)$ & $2.20(\mathrm{SD} \pm 1.35)$ & $2.13(\mathrm{SD} \pm 1.27)$ \\
\hline Non-HDL-C $(\mathrm{mmol} / \mathrm{L})$ & $4.20(\mathrm{SD} \pm 1.27)$ & $4.51(\mathrm{SD} \pm 1.65)$ & $4.32(\mathrm{SD} \pm 1.43)$ \\
\hline
\end{tabular}

Non-fasting lipid profiles performed within 24 hours of acute myocardial infarction. HDL-C = High-density lipoprotein cholesterol, LDL-C = Low-density lipoprotein cholesterol, SD $=$ Standard deviation. "p value for significance of difference between male and female subjects.

\section{TABLE III: Effect of pre-existing statin therapy on observed lipid values and myocardial infarction.}

\begin{tabular}{|c|c|c|c|}
\hline Finding & $\begin{array}{l}\text { On statin therapy } \\
\qquad(\mathrm{n}=80)\end{array}$ & $\begin{array}{l}\text { Not on statin therapy } \\
\qquad(n=30)\end{array}$ & P value \\
\hline Total cholesterol (mmol/L) & $5.44(\mathrm{SD} \pm 1.45)$ & $5.82(\mathrm{SD} \pm 1.29)$ & 0.207 \\
\hline LDL-C (mmol/L) & $3.43(\mathrm{SD} \pm 1.26)$ & $4.03(S D \pm 1.10)$ & 0.023 \\
\hline $\mathrm{HDL}-\mathrm{C}(\mathrm{mmol} / \mathrm{L})$ & $1.01(S D \pm 0.31)$ & $1.12(\mathrm{SD} \pm 0.38)$ & 0.127 \\
\hline Triglycerides (mmol/L) & $2.27(\mathrm{SD} \pm 1.34)$ & $1.98(\mathrm{SD} \pm 1.09)$ & 0.287 \\
\hline Non-HDL-C (mmol/L) & $4.43(\mathrm{SD} \pm 1.37)$ & $4.70(S D \pm 1.17)$ & 0.332 \\
\hline Mean number of lipid abnormalities & 2.3 & 2.4 & 0.345 \\
\hline Premature CAD & $51(63.8 \%)$ & $18(60.0 \%)$ & 0.717 \\
\hline Type of infarct & & & 0.029 \\
\hline NSTEMI & $53(66.3 \%)$ & $13(43.3 \%)$ & \\
\hline STEMI & $27(33.8 \%)$ & $17(56.7 \%)$ & \\
\hline Admission troponin ng/L & $3733(\mathrm{SD} \pm 26008)$ & $3844(S D \pm 13100)$ & 0.982 \\
\hline Admission CPK u/L & $646(S D \pm 817)$ & $1084(S D \pm 1903)$ & 0.094 \\
\hline
\end{tabular}

LDL-C = Low-density lipoprotein cholesterol, HDL-C = High-density lipoprotein cholesterol, CAD = Coronary artery disease, NSTEMI = Non-ST elevation myocardial infarction, STEMI = ST-elevation myocardial infarction, $C P K=$ Creatine phosphokinase, $S D=$ Standard deviation. "Denotes p value when comparing pre-existing versus no pre-existing statin therapy. 


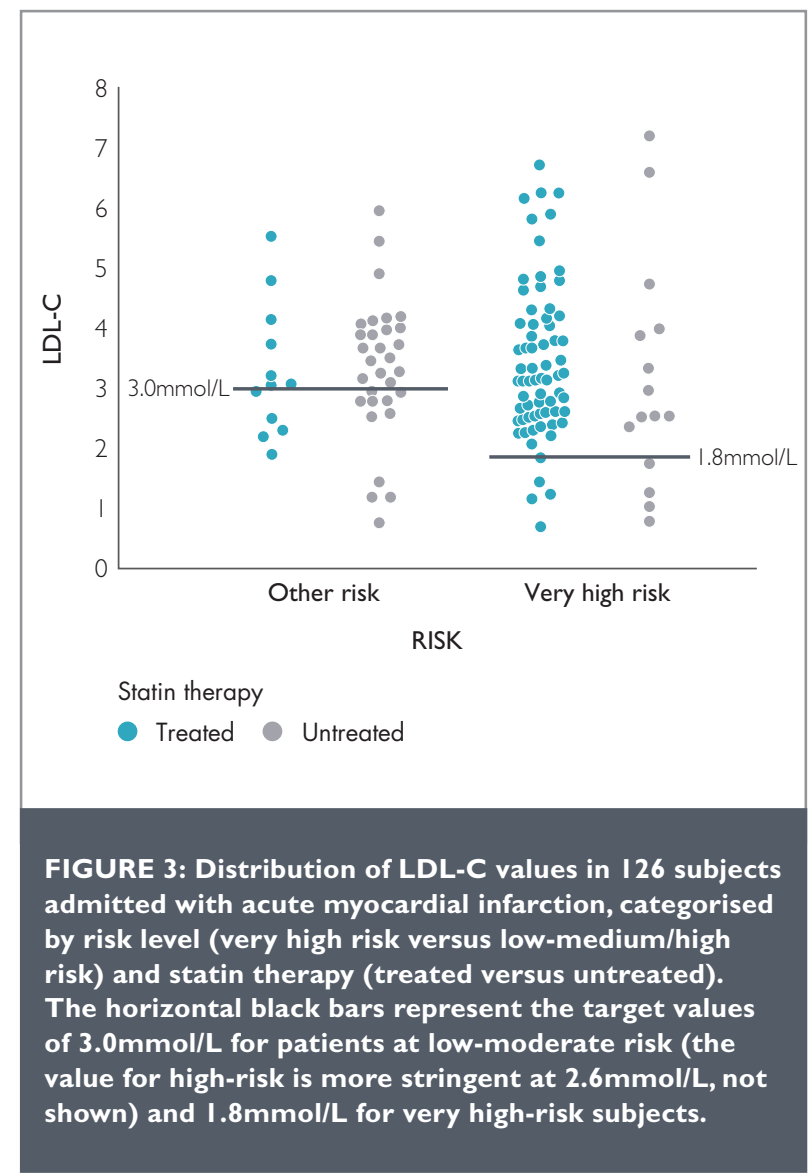

\section{DISCUSSION}

Nearly all subjects were of Indian descent. Though this is in keeping with previous studies showing South African Indian subjects to be a high-risk population for CAD, with a high prevalence of hyperlipidaemia, ${ }^{(10-12)}$ the prevalence we found is likely to have been influenced by the surrounding population of our hospital, which serves an area with a large Indian population. Most subjects in this study were shown to have hyperlipidaemia, with $63.5 \%$ having a pre-existing diagnosis of hyperlipidaemia and $23.8 \%$ subjects a new diagnosis (Table I). Increased TC, LDL-C and non-HDL-C levels, with decreased levels of HDL-C, were seen in most subjects in this study indicating poor lipid control. Elevated non-HDL-C may be a risk indicator for CVD and the mean level in our study population was 4.43 , with the target value being less than $2.6 \mathrm{mmol} / \mathrm{L}$. ${ }^{(13)}$ A large number of subjects previously diagnosed with hyperlipidaemia had poorly controlled lipid levels, despite being on statin therapy (Table $V$ ). Those treated with statins did show a significant reduction in LDL-C levels compared with untreated subjects, albeit in many cases the target values were not achieved. For subjects with DM and established CAD (very high-risk category) who have been on statin therapy, the target value for LDL-C $(<1.8 \mathrm{mmol} / \mathrm{L})$ had not been achieved in $94 \%$. Furthermore, a high proportion of the entire group had lipid

TABLE IV: Effect of diabetes mellitus on lipid profile and pattern of infarction.

\begin{tabular}{|c|c|c|c|c|c|c|}
\hline & $\begin{array}{l}\text { Non-DM } \\
(n=49)\end{array}$ & $\begin{array}{l}\text { All DM } \\
\left(n=77^{*}\right)\end{array}$ & P value & $\begin{array}{l}\mathrm{HbA}_{\mathrm{lc}} \leq 7.0 \% \\
(\mathrm{n}=12,15.6 \%)\end{array}$ & $\begin{array}{c}\mathrm{HbA}_{1 \mathrm{c}}>7.0 \\
(\mathrm{n}=51,66.2 \%)\end{array}$ & P value \\
\hline $\begin{array}{l}\text { Total cholesterol } \\
(\mathrm{mmol} / \mathrm{L})\end{array}$ & $5.12(1.34)$ & $5.43(\mathrm{SD} \pm 1.56)$ & 0.25 & $6.03(\mathrm{SD} \pm 1.53)$ & $5.36(\mathrm{SD} \pm 1.63)$ & 0.246 \\
\hline LDL-C (mmol/L) & $3.27(\mathrm{SD} \pm 1.13)$ & $3.45(\mathrm{SD} \pm 1.43)$ & 0.64 & $4.13(\mathrm{SD} \pm 1.26)$ & $3.33(\mathrm{SD} \pm 1.38)$ & 0.484 \\
\hline HDL-C (mmol/L) & $0.99(\mathrm{SD} \pm 0.32)$ & $1.06(S D \pm 0.32)$ & 0.26 & $1.06(S D \pm 0.18)$ & $1.07(S D \pm 0.31)$ & 0.245 \\
\hline Triglycerides (mmol/L) & $1.95(\mathrm{SD} \pm 1.29)$ & $2.24(\mathrm{SD} \pm 1.25)$ & 0.20 & $1.74(S D \pm 0.94)$ & $2.26(\mathrm{SD} \pm 1.23)$ & 0.215 \\
\hline Non-HDL-C (mmol/L) & $4.13(S D \pm 1.22)$ & $4.44(\mathrm{SD} \pm 1.54)$ & 0.30 & $4.97(\mathrm{SD} \pm 1.55)$ & $4.40(\mathrm{SD} \pm 1.62)$ & 0.225 \\
\hline TC:HDL-C ratio & $5.44(S D \pm 1.46)$ & $5.42(\mathrm{SD} \pm 1.73)$ & 0.98 & $5.80(\mathrm{SD} \pm 1.63)$ & $5.26(\mathrm{SD} \pm 1.70)$ & 0.947 \\
\hline LDL-C:HDL-C ratio & $3.46(S D \pm 1.20)$ & $3.50(\mathrm{SD} \pm 1.85)$ & 0.87 & $4.00(S D \pm 1.31)$ & $3.29(\mathrm{SD} \pm 1.43)$ & 0.907 \\
\hline $\begin{array}{l}\text { Subjects with lipid profile } \\
\text { below target value }\end{array}$ & $8(16.3 \%)$ & $8(10.4 \%)$ & 0.41 & I (8.3\%) & $7(13.7 \%)$ & 0.329 \\
\hline $\begin{array}{l}\text { Subjects with } \\
\text { hyperlipidaemia }\end{array}$ & 41 (83.7\%) & $69(89.6 \%)$ & & II (91.7\%) & $44(86.3 \%)$ & 0.329 \\
\hline Type of infarct & & & 0.009 & & & \\
\hline NSTEMI & $23(47 \%)$ & $54(70 \%)$ & & & & \\
\hline STEMI & $26(53 \%)$ & $23(30 \%)$ & & & & \\
\hline
\end{tabular}

TC = Total cholesterol, HDL-C = High-density lipoprotein cholesterol, LDL-C = Low-density lipoprotein cholesterol, NSTEMI = Non-ST elevation myocardial infarction, STEMI = ST-elevation myocardial infarction, DM = Diabetes mellitus. "HbA $A_{l c}$ values are unknown for 14 subjects (18.2\%) with diabetes mellitus. "p value for significance of difference between diabetic and non-diabetic subjects. ${ }^{* * *} p$ value for significance of difference between diabetic subjects with $\mathrm{HbA}_{\mathrm{lc}}$ values $\leq 7 \mathrm{mmol} / \mathrm{L}$ or $>7 \mathrm{mmol} / \mathrm{L}$. 
TABLE V: Subjects whose LDL-C levels fall within recommended target values.

\begin{tabular}{|c|c|c|c|}
\hline & $\begin{array}{l}\text { Very high risk } \\
\text { (Target } \\
<1.8 \mathrm{mmol} / \mathrm{L})\end{array}$ & $\begin{array}{c}\text { Low- } \\
\text { moderate or } \\
\text { high risk } \\
\text { (Target } \\
<3.0 \mathrm{mmol} / \mathrm{L} \text { ) }\end{array}$ & Total \\
\hline All & 83 & 43 & 126 \\
\hline On target & $8(9.6 \%)$ & I5 (34.9\%) & 23 (18.3\%) \\
\hline $\begin{array}{l}\text { On statin } \\
\text { therapy }\end{array}$ & 68 & 12 & 80 \\
\hline $\begin{array}{l}\text { On target (\% } \\
\text { of those on } \\
\text { statin therapy) }\end{array}$ & $4(5.9 \%)$ & $5(41.7 \%)$ & $9(11.2 \%)$ \\
\hline
\end{tabular}

Subjects classified as very high risk are those with a history of previous acute coronary syndrome or diabetes mellitus. The low-medium and high-risk categories could not be distinguished owing to a lack of historical information. The subjects counted as "on target" are those whose LDL-C values fell below $1.8 \mathrm{mmol} / \mathrm{L}$ if in the very-high-risk category, and below $3.0 \mathrm{mmol} / \mathrm{L}$ if in the low-medium or high-risk categories. These 2 categories could not be distinguished on the information available. The target level set for subjects at low-medium risk in terms of the South African Dyslipidaemia Guidelines Consensus Statement, is $3.0 \mathrm{mmol} / \mathrm{L}$.

values which exceeded those recommended for their risk category, irrespective of statin therapy, placing them at a higher risk of CAD. Subjects taking lipid-lowering therapy were less likely to experience a STEMI and more likely to present with NSTEMI. No patients were receiving fibrates or other lipidlowering agents, despite the apparent suboptimal response to statin therapy and high TG levels in 10 subjects. Lipid values in subjects with a previous AMI did not differ significantly from those with a first presentation of AMI, and were not more likely to have an LDL-C value within the range recommended for their risk category.

Atherosclerotic CVD is associated with a number of risk factors. Hyperlipidaemia, hypertension and cigarette smoking together, are associated with a 7-fold increase risk for ACS.(14) The mean number of risk factors in our subjects was 3.45 , equating to a high-risk population for CAD. In other local studies, Masina, et al. reported smoking, hypertension and DM as being the most prevalent risk factors for CAD in the African community of South Africa, while Chetty and Ross, et al. reported smoking, DM and family history of CAD as prominent cardiovascular risk factors in the Indian population. ${ }^{(15,16)}$ In our study, hyperlipidaemia was the most prevalent risk factor, with $87.3 \%$ of all cases having abnormal lipid profiles. We found no gender predisposition for hyperlipidaemia. Hypertension and DM were also frequently encountered. Despite an extensive national anti-smoking programme in place since 1993, including a complete ban on tobacco advertising and the inclusion of health warnings on packaging, $71.8 \%$ of males in our study had a smoking history.
Most of our subjects were male. It is known that there is a gender difference in the rates of CAD, with men having a $40 \%$ higher risk of dying from any form of CAD than women. ${ }^{(17)}$ Smoking was also found to be more prevalent in males than females - resulting in men having an added risk factor for CVD. (18,19) Additional determinants may be differences in exposure to other risk factors and the cardio-protective effects of oestrogen in the female sub-population. A reduction in oestrogen production in post-menopausal women changes the lipid metabolism toward a more atherogenic form by increasing TC, LDL-cholesterol and triglyceride level, with a reduction in HDL cholesterol.(20) In our study, however, females presented with premature CAD more frequently than males, and a possible explanation for this lies in the observation that female subjects had a higher prevalence of other risk factors, including hypertension and DM, as has also been shown in the Phoenix Lifestyle project. $^{(21)}$

The high incidence of DM in our subjects may be a major cause of secondary dyslipidaemia. ${ }^{(5)}$ Subjects with type 2 DM have an increased risk of CAD, the risk increasing 2 - 3-fold for men and 3 - 5-fold for women. Patients with DM have a worse outcome following AMI than normoglycaemic individuals. ${ }^{(22)}$ Lipid disturbances are common in DM, and effective management of DM is associated with an improvement in lipid profile. ${ }^{(23,24)}$ Since lipid disturbances contribute to the development of atherosclerosis and CAD, management of hyperlipidaemia in subjects with DM is crucial. Adequate management should result in lipid levels that are similar to non-diabetic patients. We demonstrated a high percentage of subjects with pre-existing DM. Females had a significantly higher prevalence of DM (72.9\%), and $\mathrm{HbA}_{\mathrm{lc}}$ levels were significantly higher than those in males. Most subjects with DM had suboptimal glycated haemoglobin values, implying poor diabetic control; only I5.6\% of subjects had glycated haemoglobin values at target. The association between DM and poor lipid profiles is well documented, and yet in our study we found no difference in mean lipoprotein values between the 2 groups. A previous South African study showed that $93.5 \%$ of diabetic subjects treated with lipid-lowering therapy did not reach lipid target values, and no significant relationship was found between $\mathrm{HbA}_{\mathrm{Ic}}$ and any of the lipid parameters. ${ }^{(25)}$ In our study, 15 of the subjects with diagnosed DM were not on statin therapy, and for those who were on statin therapy, a high number were not at treatment target values for LDL-C - indicating an overall poor lipid control. Furthermore, an inappropriate diet, together with lack of exercise and obesity, may have contributed to the abnormal lipid status, but these factors were not evaluated in this study. Though DM has been recognised as a complication of 
statin therapy itself, the incidence of this is thought to be extremely low, and the association between statin use and DM has not been shown to be causal. ${ }^{(26,27)}$ We therefore believe that the high prevalence of DM in our study is a true reflection of its actual prevalence, and is not artificially increased by statin therapy.

\section{LIMITATIONS}

This is a retrospective chart audit at a single centre, with no control group. Our findings may be strengthened by expanding the study to include a larger population at multiple sites. The study focused on a number of risk factors, particularly hyperlipidaemia, but was not designed to provide data in detail for other risk factors such as obesity, hypertension, quantification of smoking exposure, and treatment compliance. We were unable to perform accurate risk stratification owing to lack of data. Angiography is not available at this hospital, and we were unable to correlate glycaemic and lipid control with extent of disease. Lack of information about prior statin dose prevented us from analysing more closely the relationship between statin therapy and lipid levels noted on admission. We did not collect information on other pre-existing therapy such as antiplatelet and anti-remodelling therapy. This was not part of the study as originally planned, and the extent of failure of secondary prophylaxis in subjects with a previous AMI, only became apparent as results emerged.

Though the European Society of Cardiology guidelines suggest that a non-fasting lipogram is as predictive of risk as a fasting lipogram, there is evidence that the LDL-C value may be up to $0.6 \mathrm{mmol} / \mathrm{L}$ lower in non-fasting than in fasting samples. ${ }^{(28)}$ This may have led to our LDL-C values being slightly conservative, with an overall higher risk than would otherwise be inferred.

\section{CONCLUSIONS}

In conclusion, we demonstrated a high prevalence of hyperlipidaemia in subjects presenting with an AMI. The subjects in the population studied demonstrated multiple risk factors. A major finding has been the very high prevalence of potentially modifiable risk factors, particularly hyperlipidaemia, DM, hypertension and smoking. Subjects with DM have elevated glycated haemoglobin levels, and there is a high rate of hyperlipidaemia - with over $80 \%$ of subjects having LDL-C levels that exceed the SADGCS-recommended target levels, even when treated with statins. Our findings suggest that potentially modifiable risk factors may have been inadequately addressed, indicating possible failures in both primary and secondary prophylaxis. Glycated haemoglobin and lipid levels that are no better in those with a previous AMI than in those with a first AMI, support our view that, in these subjects, secondary prophylaxis has not resulted in optimal metabolic outcomes.

\section{RECOMMENDATIONS}

Our findings support the need for the current national screening programme for DM and hypertension and we suggest that this be expanded to include screening for hyperlipidaemia. Strengthening primary healthcare to ensure adequate primary prevention of IHD by effective control of modifiable risk factors for CAD needs urgent attention as we have demonstrated this to be a problem in the subjects studied. Once identified, subjects need to be commenced on effective treatment, and be treated to target. In addition to pharmacotherapy, interventions are required to improve drug availability, adherence to medication, and to bring about lifestyle modifications including appropriate diet, regular exercise and smoking cessation. Though use of a combined pill (the "polypill") consisting of aspirin, statin and antihypertensive has been reported as being associated with improved compliance, ${ }^{(29-33)}$ a Cochrane review has suggested that the evidence is not as yet conclusive, and that further studies are necessary to establish its utility. ${ }^{(34)}$ Many newer lipid-lowering agents are under development and a few, such as the proprotein convertase subtilisin/kexin type 9 (PCSK9) inhibitors, are now approved for use elsewhere, though not in South Africa. ${ }^{(35)}$ Availability of alternate treatment for subjects unable to tolerate first line statin therapy may improve lipid control in these subjects.

\section{ACKNOWLEDGEMENTS}

We acknowledge the help of Prof R. Hift with the preparation of the manuscript.

\section{Conflict of interest: none declared.}


I. Mendis S, Thygesen K, Kuulasmaa K, et al. World Health Organisation definition of myocardial infarction: 2008-09 revision. International Journal of Epidemiology 201 1;40:139-146.

2. Peer N, Steyn K, Dennison CR, et al. Determinants of target organ damage in black hypertensive patients attending primary health care services in Cape Town: The Hi-Hi study. Am J Hypertens 2008;21:896-902.

3. Laurence $E$, Lombard L, Volmink J. Risk factors for myocardial infarction and stroke in Africa: Risk factor profile in Africa. South African Heart Journal 201 1;8:12-23.

4. Yusuf S, Hawken S, Ounpuu S, et al. Effect of potentially modifiable risk factors associated with myocardial infarction in 52 countries (the INTERHEART study): Case-control study. Lancet 2004;364:937-952.

5. Klug E, Raal F, Marais A, et al. South African dyslipidaemia guideline consensus statement. South African Heart Journal 2017;9:106-117.

6. Levine GN, Keaney JF, Vita JA. Cholesterol reduction in cardiovascular disease - clinical benefits and possible mechanisms. New England Journal of Medicine 1995;332:512-521.

7. Koro CE. The independent correlation between high-density lipoprotein cholesterol and subsequent major adverse coronary events. Am Heart J 2006; | 51:755.

8. Mihaylova B, Emberson J, Blackwel I, et al. The effects of lowering LDL cholesterol with statin therapy in people at low risk of vascular disease: Meta-analysis of individual data from 27 randomised trials. Lancet 2012: 380:581-590

9. McKenney JM. Update on the National Cholesterol Education Programme Adult Treatment Panel III guidelines: Getting to goal. Pharmacotherapy 2003;23:26S-33S

10. Seedat $Y$, Mayet F, Khan S, et al. Risk factors for coronary heart disease in the Indians of Durban. South African Medical Journal 1990;78:442-454.

I I. Ranjith N, Verho NK, Verho M, et al. Acute myocardial infarction in a young South African Indian-based population: Patient characteristics on admission and gender-specific risk factor prevalence. Curr Med Res Opin 2002; | 8:242-248.

12. Ranjith N, Pegoraro RJ, Naidoo DP. Demographic data and outcome of acute coronary syndrome in the South African Asian Indian population. Cardiovasc J S Afr 2005; 16:48-54

13. Catapano AL, Graham I, De Backer G, et al. 2016 ESC/EAS guidelines for the management of dyslipidaemias. Eur Heart J 2016;37:2999-3058.

14. Kumar V, Abbas AK, Aster JC. Robbins and Cotran pathologic basis of disease, 9th edn. Philadephia, PA: Elsevier Saunders; 2015.

15. Chetty R, Ross A. Chart review of acute myocardial infarction at a district hospital in KwaZulu-Natal, South Africa. African Journal of Primary Health Care \& Family Medicine 2016;8:1-5

16. Masina S, Sartorius B, Ranjith N. Risk factor assessment in South African Black patients presenting with acute myocardial infarction at RK Khan Hospital, Durban: Risk factor assessment. South African Heart Journal 2016;13:12-18.

17. Engberding N, Wenger NK. Gender differences in coronary risk factors and risk interventions. In: Atlas of Atherosclerosis and Metabolic Syndrome. Springer; 2011:253-299.

18. Jonas MA, Oates JA, Ockene JK, et al. Statement on smoking and cardiovascular disease for health care professionals. American Heart Association. Circulation 1992;86:1664-1669.

19. Ockene IS, Miller NH. Cigarette smoking, cardiovascular disease, and stroke: A statement for healthcare professionals from the American Heart Association. American Heart Association Task Force on Risk Reduction. Circulation 1997;96:3243-3247

20. Sowers JR, Epstein M, Frohlich ED. Diabetes, hypertension, and cardiovascular disease: An update. Hypertension 200 I;37:1053-1059.

21. Prakaschandra DR, Esterhuizen TM, Motala AA, et al. High prevalence of cardiovascular risk factors in Durban South African Indians: The Phoenix Lifestyle Project. South African Medical Journal 2016;106:284-289.

22. Grundy SM, Benjamin IJ, Burke GL, et al. Diabetes and cardiovascular disease: A statement for healthcare professionals from the American Heart Association. Circulation 1999;100:1 134-1146.
23. Ozder A. Lipid profile abnormalities seen in T2DM patients in primary healthcare in Turkey: A cross-sectional study. Lipids in Health and Disease 2014;13:183.

24. Nesto RW. LDL cholesterol lowering in type 2 diabetes: What is the optimum approach? Clinical Diabetes 2008;26:8-13.

25. Daya R, Bayat Z, Raal F. Prevalence and pattern of dyslipidaemia in type 2 diabetes mellitus patients at a tertiary care hospital. Journal of Endocrinology, Metabolism and Diabetes of South Africa 2017;22:31-35.

26. Shah RV, Goldfine AB. Statins and risk of new-onset diabetes mellitus. Circulation 2012;126:e282-e4.

27. Aiman U, Najmi A, Khan RA. Statin induced diabetes and its clinical implications. J. Pharmacol. Pharmacother. 2014;5:181.

28. Langsted A, Nordestgaard BG. Nonfasting lipids, lipoproteins, and apolipoproteins in individuals with and without diabetes: 58434 individuals from the Copenhagen General Population Study. Clinical Chemistry 2011; 57:482-489.

29. Selak V, Webster R, Stepien S, et al. Reaching cardiovascular prevention guideline targets with a polypill-based approach: A meta-analysis of randomised clinical trials. Heart 2018.

30. Rosenthal T. Can a polypill one single tablet combat different cardiovascular risk factors? J Am Soc Hypertens 20 1 8; 12:335-339.

31. Yusuf S, Lonn E, Pais P, et al. Blood-pressure and cholesterol lowering in persons without cardiovascular disease. New England Journal of Medicine 2016;374:2032-2043.

32. Lonn E, Bosch J, Teo KK, et al. The polypill in the prevention of cardiovascular diseases: Key concepts, current status, challenges, and future directions. Circulation 2010; I22:2078-2088.

33. Wald NJ, Law MR. A strategy to reduce cardiovascular disease by more than 80\%. British Medical Journal 2003;326:1419.

34. de Cates AN, Farr MRB, Wright N, et al. Fixed-dose combination therapy for the prevention of cardiovascular disease. Cochrane Database of Systematic Reviews 20 14:4:CD009868-CD.

35. Brozin D, Raal F. Novel approaches to lipid-lowering therapy. South African Medical Journal 20I8; 108:262-265. 